\title{
Lessons to be learned from the prevalence of COVID-19 in Iran
}

\author{
Mona Omidi ${ }^{1}$, Ali Maher*2 ${ }^{(\mathbb{D}}$, Samira Etesaminia $^{3}$ \\ Received: 14 Mar 2020 \\ Published: 28 May 2020
}

Conflicts of Interest: None declared

Funding: None

\section{*This work has been published under CC BY-NC-SA 1.0 license. \\ Copyright $@$ Iran University of Medical Sciences}

Cite this article as: Omidi M, Maher A, Etesaminia S. Lessons to be learned from the prevalence of COVID-19 in Iran. Med J Islam Repub Iran. 2020 (28 May);34:54. https://doi.org/10.47176/mjiri.34.54

\section{Introduction}

Corona virus, a pandemic infection (1), has involved the global community, especially health policymakers. Coronaviruses $(\mathrm{CoV})$, a large family of viruses and a subset of the Coronaviridae, were first discovered in 1965 (2) and found to cause illnesses ranging from the common cold to more severe diseases such as Middle East respiratory syndrome (MERS-CoV) and severe acute respiratory syndrome (SARS-CoV) (3).

New coronavirus is perhaps the most ambitious, agile, and aggressive disease in history (1). On December 31, 2019, the WHO Office in China was informed of cases of pneumonia with unknown etiology (unknown cause) in Wuhan, Hubei province, China (4).

China made several interventions against this epidemic. For example, national authorities searched for active cases in all provinces. The search expanded for additional cases both inside and outside Wuhan for active and retroactive cases. Accordingly, the Human Seafood Wholesale Market closed down in Wuhan on January $1^{\text {st }} 2020$ for environmental sanitation as well as disinfecting measures. Also, public education and environmental hygiene was strengthened (4). In a recent report from China, chest CT scan showed a sensitivity of $97 \%$ for diagnosing COVID19, which was superior to RT-PCR (5).

On January 20, 2020, National IHR Focal Point (NFP) for Republic of Korea reported the first case of COVID19. The patient was a 35-year-old female, Chinese national who resided in Wuhan, Hubei province, in China (6).

The Republic of Korea responded to this public health epidemic by taking various measures. Contact tracing and other epidemiological investigations were done, the government scaled up the national alert level from blue (Level 1) to yellow (Level 2 out of 4-Level national crisis management system), and the health authorities increased the surveillance for pneumonia cases in health facilities nationwide as of January 3, 2020. Moreover, quarantine and screening measures were enhanced for travelers from $\mathrm{Wu}-$ han at the entry points $(\mathrm{PoE})(4,6)$.

On January 31, 2020, the first 2 confirmed cases of COVID-19 acute respiratory diseases were reported in Italy; both cases had a travel history to Wuhan. Then, 16 days after the first report of COVID-19 in Italy, the government took important steps to quarantine 16 million people in 14 provinces in the north of the country to prevent the spread of the virus throughout the country (7).

For example, traveling in and out of an area was only possible under certain conditions; people with symptoms of respiratory diseases and fever of 37.5 Celsius or above were strongly encouraged to stay at home; gatherings were prohibited; all schools, universities, museums, and cultural places, shopping centers, etc. were closed; and all sporting events and competitions were suspended (7). This epidemic also shocked the Italian political leaders, as 11 cities in northern Italy were officially quarantined (quarantine at 4 levels) and residents were threatened to quarantine if they tried to break any levels of the quarantine (1).

In Iran, on February 20, 2020, the Ministry of Health and Medical Education confirmed 2 COVID-19 cases in Qom as the epicenter of the disease (8). Then, due to insufficient information and the lack of awareness about the spread of the virus and not believing in vulnerability, the disease spread rapidly in Tehran as a commercial center and in the northern parts of Iran because of their tourism and travel attraction. The behavior of the virus is unknown due to its novelty, and given that the information released by China had many shortcomings and was incomprehensible, more research is needed. In Iran, COVID-19 spread more rapidly due to the arrival of the Persian New Year 
(Nowruz). Most of health care personnel encountered the illness at 3 levels: low, moderate, and severe. Unfortunately, a significant number of nurses and service personnel died of COVID-19. In addition, Iran was not prepared to deal with this epidemic crisis due to the US sanctions, lack of logistics and protective equipment, insufficient disinfecting supplies, lack of specialized beds and internal specialists, and poor primary health care (PHC) in cities. The available facilities do not correspond to the increasing prevalence of the disease in the community. Measures taken so far include equipping hospitals to accommodate COVID-19 patients, increasing the capacity of hospitals, and taking steps to develop field hospitals. The relationship between levels 1 and 2 based on the Health Intelligent Management system, creating an online screening system, and contact tracing, along with proper handwashing training campaigns have been effective in controlling the spread of the virus. Meanwhile, the closure of schools, universities, and public event centers, and most importantly, the creation of an integrated health information database have led to an effective management of the crisis so far.

Also, during the grassroots movement, a group of citizens have taken impressive steps toward preventing the spread of the disease; for instance, a group of doctors started treating patients online to stop the flood of patients to clinics and hospitals. Women can join this movement by sewing masks and donating them to medical centers. Also, people can disinfect urban facilities like ATMs at nights to prevent the spread of this virus.

The spread of the virus to other cities can be prevented by actively screening and focusing on nonvirtual and virtual activities and recommending quarantining the entire country. The medical personnel are the most susceptible carriers of the disease in the community, and if not protected, they can spread the virus first to their families and then to the whole community. Therefore, investing in the protection of these people and separating them from the public transport is one of the priorities in the fight against this disease outbreak in Iran. For this purpose, medical staff can use hotels; moreover, patient safety measures should be improved (9).

Face to face, communication can have a direct impact on the mortality rate of COVID-19 if social distancing is not taken seriously. Therefore, it is imperative for all countries to quarantine their epicenter right from the start to prevent the rapid spread of the disease, which will have irreparable consequences.

\section{Conflict of Interests}

The authors declare that they have no competing interests. -ncov.pdf?sfvrsn=4d5bcbca_2

5. Ai T, Yang Z, Hou H, Zhan C, Chen C, Lv W, et al. Correlation of chest CT and RT-PCR testing in coronavirus disease 2019 (COVID19) in China: A report of 1014 cases. Radiology. 2020:200642.

6. World Health Organization. Novel coronavirus - Republic of Korea (ex-China). Accessed March 10, 2020. https://www.who.int/csr/don/ 21-january-2020-novel-coronavirus-republic-of-korea-ex-china/en/

7. worldometers. Accessed March 11, 2020. https://www.worldometers. info/coronavirus/

8. World Health Organization. Novel coronavirus (2019-nCoV): situation report- 31. Accessed March 10, 2020. https://www.who.int/docs/ default-source/coronaviruse/situation-reports/20200220-sitrep-31COVID-19.pdf?sfvrsn=dfd11d24 2

9. Maher A, Ayoubian A, Rafiei S, Sheibani Tehrani D, Mostofian F, Mazyar P. Developing strategies for patient safety implementation: a national study in Iran. Int $\mathrm{J}$ Health Care Qual Assur. 2019;32(8):1113-1131.

\section{References}

1. COVID-19: too little, too late? Editorial. Lancet. 2020;395:755.

2. Tyrrell DA. Cultivation of a novel type of common-cold virus in organ cultures. Br Med J. 1995;1(5448):1467-70.

3. World Health Organization. Accessed March 10, 2020. https://www.who.int/health-topics/coronavirus

4. World Health Organization. Novel coronavirus (2019-nCoV): situation report- 2. Accessed March 10, 2020. https://www.who.int/docs/ default-source/coronaviruse/situation-reports/20200122-sitrep-2-2019 